\title{
Peribulbar anaesthesia during keratoplasty: a prospective study of 100 cases
}

\begin{abstract}
Marc Muraine, Emile Calenda, Laure Watt, Nicole Proust, Annie Cardon, Laurent Eupherte, Gérard Brasseur
\end{abstract}

anaesthesia $^{4-6}$ or peribulbar anaesthesia. ${ }^{7}$ To date, two papers ${ }^{78}$ reported cases of keratoplasties performed under peribulbar anaesthesia in their group but failed to describe surgical conditions and to specifically analyse efficacy of this type of anaesthesia during this surgery.

As most patients underwent keratoplasty under peribulbar anaesthesia in our centre, we conducted a prospective study in order to describe the development of such a procedure. To our knowledge this is the first reported study to describe surgical conditions occurring during keratoplasty performed under peribulbar anaesthesia and to specifically analyse the efficacy and safety of peribulbar anaesthesia during keratoplasty.

\section{Patients and methods}

We prospectively studied 100 keratoplasties performed at our institution under peribulbar anaesthesia by one surgeon from September 1995 to June 1997. As 137 patients were grafted in the time course of our study, peribulbar anaesthesia represented $73 \%$ of all anaesthesia performed in keratoplasties (100/ 137) whereas general anaesthesia represented $27 \%(37 / 137)$.

General anaesthesia was systematically proposed and performed in patients under 25 years of age (14 patients). Patients over 25 years (123 patients) had peribulbar anaesthesia whatever the surgical protocol and clinical indications except for patients with respiratory insufficiency and when decubitus was impossible.

Thirty nine per cent $(15 / 38)$ of patients between 25 and 49 years refused local anaesthesia or were judged to be too anxious by the anaesthetist. Nine per cent (8/85) of patients over 50 years had difficulty lying down for a long period of time because of back or respiratory problems and therefore underwent general anaesthesia. Finally, consent for peribulbar anaesthesia was obtained in 100 patients out of $123(81.3 \%)$.

Table 1 shows the demographic data of the 137 grafted patients.

Figure 1 represents the type of anaesthesia according to age.

Table 2 represents the type of anaesthesia according to preoperative diagnosis.

Surgical protocols are outlined in Table 3.

As standard premedication, all patients received hydroxyzine (1-2 $\mathrm{mg} / \mathrm{kg}$ body weight), or flunitrazepam $(0.01-0.02 \mathrm{mg} / \mathrm{kg}$ body weight) 2 hours preoperatively. A short acting sedative was administered 5 minutes before injection in 26 patients who presented with 


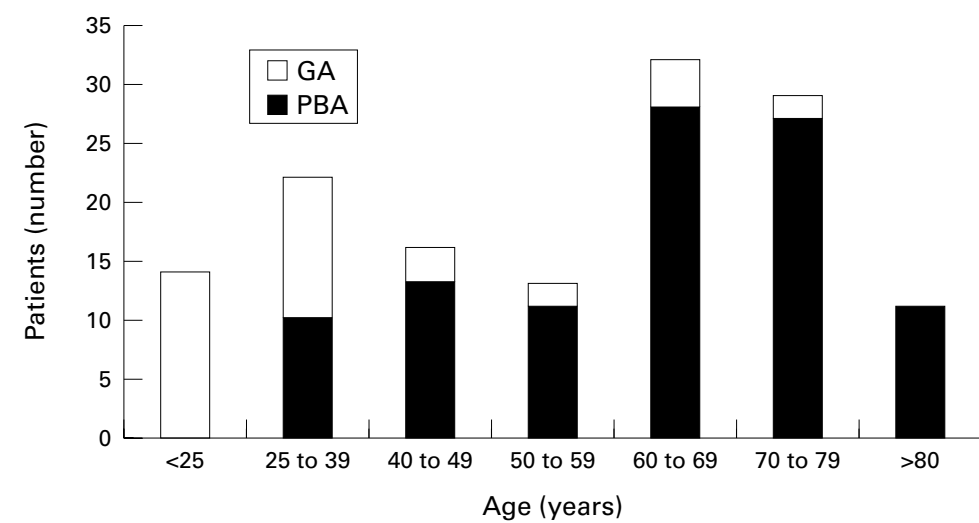

Figure 1 Type of anaesthesia according to age ( $G A=$ general anaesthesia, $P B A=$ peribulbar anaesthesia).

Table 2 Type of anaesthesia and preoperative diagnosis

\begin{tabular}{lcc}
\hline & $\begin{array}{l}\text { Peribulbar } \\
\text { anaesthesia } \\
\text { (100 patients) }\end{array}$ & $\begin{array}{l}\text { General anaesthesia } \\
\text { (37 patients) }\end{array}$ \\
\hline Pseudophakic bullous keratopathy & 40 & $4(10.8 \%)$ \\
Fuchs' dystrophy & 17 & $2(5.4 \%)$ \\
Keratoconus & 11 & $21(56.8 \%)$ \\
Regraft & 8 & $4(10.8 \%)$ \\
Herpetic keratopathy & 6 & 1 \\
Corneal scar & 5 & 2 \\
Miscellaneous & 13 & 3 \\
\hline
\end{tabular}

very anxious behaviour (propofol, $1 \mathrm{mg} / \mathrm{kg}$ / hour). Other patients did not require any additional treatment. An anaesthetist was present throughout surgery and all patients received oxygen. Cardiac monitoring was performed and oximetry and blood pressure were controlled in all patients throughout the procedure.

All peribulbar blocks were performed using a 50:50 mixture of $1 \%$ etidocaine and $0.5 \%$ bupivacaine with $5 \mathrm{IU} / \mathrm{ml}$ of hyaluronidase. A dual peribulbar anaesthesia (inferotemporal and superonasal injections) was performed using a 25 gauge, $35 \mathrm{~mm}$ peribulbar needle. The needle was inserted percutaneously, 25 $\mathrm{mm}$ from the skin surface. The injection is stopped when the eyelids become tense. As soon as the globe becomes soft, injection is started again until another sensation of tension of the orbit. A total volume, on average, of 10.6 (SD 3.5) $\mathrm{ml}$ (range 5-18 ml) of anaesthetic was then very slowly injected into the inferotemporal orbit and $5.3(2.71) \mathrm{ml}$ (range $0-9 \mathrm{ml}$ ) into the superonasal orbit. In order to decrease IOP before trephination a pressure balloon was applied to the orbit for at least 20 minutes. IOP values were measured with a Tonopen immediately before and after injection and then after ocular compression and before trephination. All patients had stable ocular pressure before grafting.
Motor akinesia was evaluated 25-30 minutes after injection and during surgery by asking the patient to look in various directions of gaze. Globe movements were scored according to the method described by Nicoll et al ${ }^{9}$ where 0 represents full movement of the associated rectus muscle, 1 partial movement of the associated rectus muscle, and 2 complete paralysis of the associated rectus muscle (a total of 8 ). Supplemental injections were given to patients who failed to develop extraocular muscle akinesia (total score $<7$ ) and those who retained sufficient orbicularis oculi muscle function to hinder surgery. The percentage of supplemental peribulbar block required was noted. As suggested by other authors, ${ }^{10}$ a subjective response to pain during the surgery was assessed by asking the patient to choose a number between 0 and 10 on an ordinal analogue scale, where 0 represented no pain and 10 represented the maximum pain. Patients were encouraged to inform the surgeon about pain during the surgery. Other variables observed were surgical conditions, eventual complications, and duration of surgery.

\section{Results}

The mean operating time was 52 (11) minutes (range 28-80 minutes).

Peribulbar injection caused an immediate increase in IOP averaging $17.78(2-37) \mathrm{mm}$ $\mathrm{Hg}$ (Table 4) and in some cases this increase was particularly high (IOP reached over 50 $\mathrm{mm} \mathrm{Hg}$ in 14 patients). The mean change in IOP after ocular compression was an overall decrease of $5.73 \mathrm{~mm} \mathrm{Hg}$ from the preinjection value. IOP was always below $22 \mathrm{~mm} \mathrm{Hg}$ before trephination.

\section{EFFICACY}

Complete globe akinesia was obtained in 80 patients (80\%) 20 minutes after injection (total score 8). Peribulbar block was considered as adequate in six patients with almost complete akinesia (total score 7). Fourteen patients (14\%) required supplemental peribulbar anaesthesia, 12 patients because of failure to develop akinesia of the extraocular muscles and two because of persisting orbicularis oculi muscle activity as judged by the surgeon. Following reinjection, the akinesia score was above or equal to 7 in all patients. During surgery, the akinesia was complete in 80 cases during the entire surgical procedure. In the 20 remaining cases, eye movements were limited to small jerks (total score 6 or 7 ) which did not interfere with surgery. In 11 cases, we observed the reappearance of orbicular activity at the end of the surgery but this did not affect surgical procedures.

Table 3 Type of anaesthesia and surgical procedures

\begin{tabular}{|c|c|c|}
\hline Procedures & $\begin{array}{l}\text { Peribulbar } \\
\text { anaesthesia } \\
(n=100)\end{array}$ & $\begin{array}{l}\text { General } \\
\text { anaesthesia } \\
(n=37)\end{array}$ \\
\hline Keratoplasty & 36 & 29 \\
\hline Keratoplasty + extracapsular cataract extraction + posterior chamber lens implantation & 34 & 2 \\
\hline Keratoplasty + vitrectomy + anterior chamber lens removal + trans-sclerally suture fixated posterior chamber lens implantation & 15 & 6 \\
\hline Keratoplasty $+/-$ vitrectomy + anterior chamber intraocular lens exchange & 14 & 0 \\
\hline Keratoplasty + vitrectomy + posterior chamber lens implantation into the sulcus & 1 & 0 \\
\hline
\end{tabular}


Table 4 Intraocular pressure (IOP) values measured with a Tonopen (mm Hg, mean (SD))

\begin{tabular}{llll}
\hline & $\begin{array}{l}\text { IOP } \\
\text { immediately after } \\
\text { injection }\end{array}$ & $\begin{array}{l}\text { IOP after } \\
\text { 20 minutes, } \\
\text { compression }\end{array}$ & $\begin{array}{l}\text { IOP before } \\
\text { trephination }\end{array}$ \\
\hline $15.94(3.9)$ & $33.69(12.28)$ & $10.85(4.95)$ & $11.57(4.35)$ \\
\hline
\end{tabular}

Analgesia was complete and stable throughout surgery in 94 cases (score 0 ). Four patients with pseudophakic bullous keratopathy reported mild intraoperative pain at the end of the surgery (score 2 or 3 ) each time the surgeon was holding the conjunctiva. This did not interfere with surgery. One patient with pseudophakic bullous keratopathy who received $22 \mathrm{ml}$ of anaesthetic experienced intense pain (score 8) and constant agitation 15 minutes after the beginning of surgery. Peroperative systemic sedation was then performed (propofol $1 \mathrm{mg} / \mathrm{kg} /$ hour) and surgery was completed under very calm conditions. One patient did not experience any pain but required a conversion to general anaesthesia because of an acute outburst of distress and agitation. Local anaesthesia therefore could not be evaluated during the entire period of surgery in this case.

\section{COMPLICATIONS}

One 62 year old woman who received $12 \mathrm{ml}$ of anaesthetic solution without preoperative sedation, experienced sudden distress after the trephination, at the time of lens removal. A patient, who reported at this time to feel claustrophobic, tried to sit up. After ineffective systemic sedation, general anaesthesia was performed. Her oximetry was normal during surgery but she had a drop in blood pressure from 14 to $10 \mathrm{~mm} \mathrm{Hg}$ with mild bradycardia 15 minutes after injection. We began surgery 20 minutes after blood pressure normalisation. At the time of recommencing surgery, our patient who had known risk factors of expulsive haemorrhage (systemic hypertension, cataract extraction with vitreous loss and anterior chamber implantation) presented with a severe intraoperative suprachoroidal haemorrhage. Despite the open sky situation and absence of management during these 10-15 minutes, this haemorrhage did not result in a true expulsive haemorrhage. Reformation of the anterior chamber was easy and closure of the wound was performed without posterior pressure. The patient had no postoperative pain. In the postoperative period, echography confirmed the progressive and spontaneous decrease of the haemorrhage. Posterior segment normalised in 1 month.

Positive posterior pressure was manifest only in phakic patients and especially during extracapsular extraction. This positive posterior pressure, present in $20.8 \%$ of phakic patients $(10 / 48)$ did not depend on IOP value before trephination as it appeared even in some patients with very low IOP $(<10 \mathrm{~mm} \mathrm{Hg})$. Because of the uncompensated pressure, the main intraoperative difficulty was to perform a complete capsulorhexis when open sky extracapsular cataract extraction was required. A complete continuous tear capsulotomy was impossible in seven cases out of $34(20.5 \%)$, and sometimes developed giant radial tears. However, radial tears were always stopped by the zonula. Aspiration irrigation of the cortex seemed to be complete in all cases with no vitreous loss.

Chemosis was noted in only six cases (6\%). This, however, was always moderate and never hindered the trephination with the Hanna limbal suction trephine.

No other adverse local reaction, in particular no palpebral, conjunctival, or peribulbar haemorrhage were noted. No patients suffer from retinal vascular occlusion in the postoperative days. No systemic complications were observed.

\section{SURGICAL CONDITIONS}

Ninety eight patients found peribulbar anaesthesia satisfactory or very satisfactory, and would choose the same type of anaesthesia for another keratoplasty. The only complaint was a moderate discomfort during injection in some cases or a backache because of the long decubitus. Six patients did not comment. Surgical conditions were judged to be optimal by the operating surgeon in these 98 cases. In contrast, both patients who presented with episodes of agitation were very dissatisfied with the type of anaesthesia and would prefer a general anaesthesia for further surgery. Therefore, it is understandable that the surgeon experienced more stressful conditions in these two cases.

\section{Discussion}

Peribulbar anaesthesia has increased in popularity because it provides the same anaesthetic result as a retrobulbar injection and has a lower morbidity. ${ }^{11}$ Consequently, peribulbar anaesthesia has been reported in many types of ophthalmic surgery. However, keratoplasties are very often performed under general anaesthesia, and locoregional anaesthesia is therefore used for short and minor cases or in older patients. According to Burdon and McDonnell, ${ }^{3}$ general anaesthesia is the usual anaesthetic technique during keratoplasty for 93\% of surgeons in the United Kingdom and Price et $a l^{4}$ reported a series of $78 \%$ patients grafted under general anaesthesia. In contrast Aquavella $^{12}$ and Collie ${ }^{13}$ routinely used retrobulbar anaesthesia supplemented with intravenous sedation for their series of outpatient corneal grafts. Very recently, Yavitz ${ }^{14}$ performed 90 keratoplasties using topical lignocaine, an O'Brien lid block, and $100 \mu \mathrm{g}$ of alfentanyl intravenously. In our series, $81.3 \%$ of patients over 25 years were grafted under peribulbar anaesthesia and only $26 \%$ received intravenous sedation. We decided arbitrarily to propose peribulbar anaesthesia only in patients over 25 years as younger adult patients are more anxious and present more of a challenge in achieving total akinesia than those who are older. ${ }^{15}$ As the choice of the type of anaesthesia was never influenced by the scheduled surgical protocol, the group of patients grafted under peribulbar anaesthesia include a high rate of 
combined procedures (64\%) and in fact differs greatly from the younger group of patients grafted under general anaesthesia with $21.6 \%$ of combined procedures.

Duration of surgery may be long (up to 80 minutes in our study) when associated procedures are required (64 cases/100). Moreover, contrary to cataract surgery, both akinesia and anaesthesia are necessary to proceed with comfortable and safe keratoplasty. In the same way, the entire volume of anaesthetic must be injected before the beginning of surgery as supplemental local injection is impossible after trephination. Therefore, it appears necessary to choose an anaesthetic mixture and a sufficient volume that allows the most potent and prolonged effect. In our study we used a combination of etidocaine, bupivacaine, and hyaluronidase as bupivacaine provides prolonged duration for surgery with an analgesic action of 3-12 hours ${ }^{16}$ and because the duration of akinetic action of etidocaine is longer than lignocaine. ${ }^{17}$ In contrast, the combination of lignocaine and bupivacaine, which is the most popular preparation currently used, produces a faster onset than bupivacaine in combination with etidocaine. ${ }^{18}$ Therefore, we associated hyaluronidase with improved onset time and akinesia of extraocular muscles. ${ }^{19} 20$ As our figures for akinesia and analgesia seem very much in line with those of reported in the literature, we believe that the standard combination of bupivacaine and lignocaine could produce the same satisfactory results when duration of surgery does not exceed 1 hour. However, this requires further evaluation, especially for longer operations with a risk of poor akinesia at the end of the surgery.

We injected higher volumes $(16.5(4) \mathrm{ml})$ of anaesthetic than in many previous studies of peribulbar anaesthesia used for other anterior segment surgery. ${ }^{721}$ However, as a precaution we injected the mixture very slowly and in several stages. As the injection is stopped when eyelids become tense, the volume of anaesthetic depends on the size of the orbit and differs from one patient to another. With these precautions we did not observe any retinal ischaemia or ischaemic optic neuropathy although our group of 100 patients is small compared with the incidence of $0.006-0.04 \%$ reported in the literature in peribulbar anaesthesia. ${ }^{72}$ On the other hand, we did not graft any patient with unbalanced glaucoma as external ocular compression may be sufficient to compromise ocular perfusion in these patients with prolonged high IOP. ${ }^{23}$ We did not observe any systemic complication such as cardiac or respiratory depression.

Despite high volume injected, our mean reinjection rate $(14 \%)$ was higher than reported for cataract extraction, ${ }^{122} 24$ perhaps because we strive for almost complete ocular akinesia (score 7 or 8 ) in our series. Akinesia was complete in $80 \%$ during the entire surgical procedure, and almost complete (score 6 or 7) in the remaining cases. We observed the reappearance of a small orbicular activity at the end of the surgery (11\%). Con- sequently, in our opinion peribulbar anaesthesia with lower volume could result in difficulties in some cases.

We found analgesia optimal in almost all cases as 98 out of 100 patients were very relaxed and 94 did not experience any pain at all during the whole surgical procedure. Four patients experienced little superficial corneal or conjunctival pain at the end of surgery and anaesthesia failed in one patient who needed systemic supplementation, suggesting that analgesia may be less effective when the eyes are inflamed or congested because of bullous keratopathy.

Patients reported a high satisfaction rate as 92 would choose the same type of anaesthesia. Only two patients would prefer another type of anaesthesia. Although surgical conditions were very pleasant in 98 of procedures, the situation became very stressful when patients presented with agitation after host button removal. This agitation was due to the ineffective analgesia in one case. In the other case, the agitation occurred 35 minutes after a drop in blood pressure with mild bradycardia. This could be explained either by a little diffusion of the anaesthetic into the subarachnoid space or by a vagal reflex in this claustrophobic patient.

In our series we reported no expulsive haemorrhage and an incidence of $1 \%$ of limited (non-expulsive) acute intraoperative suprachoroidal haemorrhage (AISH). The incidence of real expulsive suprachoroidal haemorrhage during penetrating keratoplasty is reported to be higher than for other intraocular procedures and ranges from $0.45 \%{ }^{4}$ to $1.08 \%{ }^{25}$ Price et al found an incidence of $0.45 \%$ in a series of 2011 keratoplasties $^{4}$ and reported an incidence of $1.0 \%$ in the eyes with preoperative anterior chamber lenses. Ingraham and co-workers ${ }^{25}$ found an increased incidence of expulsive haemorrhage $(4.3 \%)$ when keratoplasty was performed under retrobulbar anaesthesia with a mean latency period of 11 minutes from injection to the beginning of surgery. They speculated that increased episcleral venous pressure caused by retrobulbar injection may create congestion in the venous system, contributing to the haemorrhage risk. Consequently, Ingraham et al suggested a low volume peribulbar anaesthesia technique with a 30 minute latency to the start of surgery. Our lower incidence of expulsive haemorrhage and the fact that AISH did not result in a true expulsive haemorrhage despite at least $10 \mathrm{~min}$ utes without management is probably the result of the length of post-block compression. The AISH reported in our patient is related to both high agitation and known risk factors of suprachoroidal haemorrhage. This probably would not have occurred under general anaesthesia but local anaesthesia was particularly recommended in this cardiac patient. In contrast, several cases of expulsive haemorrhage have been reported when keratoplasty was performed under general anaesthesia and were directly related to the patient's "bucking" on the endotracheal tube. ${ }^{4}$ We believe that 
keratoplasty performed under peribulbar anaesthesia with a long time compression has a very low risk of developing an expulsive haemorrhage.

To confirm the effectiveness of this compression we measured IOP before trephination as it appears dangerous to remove the host button with a high posterior pressure. Because of the high volume of anaesthetics, compression was prolonged 20 minutes and more if IOP was still over $21 \mathrm{~mm} \mathrm{Hg}$. At the time of trephination, IOP was always below $21 \mathrm{~mm} \mathrm{Hg}$ despite a high volume of anaesthetic in some cases. As already reported there is a large and individually variable rise in IOP following peribulbar anaesthesia ${ }^{26}$ and increase in IOP is sometimes marked (over $50 \mathrm{~mm} \mathrm{Hg}$ ). The mean immediate rise in IOP was of $17.78 \mathrm{~mm} \mathrm{Hg}$ with a mean volume of $16.5 \mathrm{ml}$ and is higher than reported by other author $\mathrm{s}^{27}$ who found an immediate rise of $11.44 \mathrm{~mm} \mathrm{Hg}$ after injection of $10 \mathrm{ml}$ of anaesthetic. It is known that IOP shows an initial decrease to slightly less than the baseline level in the first 2.5 minutes. ${ }^{28} \mathrm{We}$ confirmed the same decrease even with higher volumes and consequently IOP was high during a very short time and was not associated in our series with retinal damages. Moreover, Hayreh and Weingeist ${ }^{29}$ have shown experimentally that the tolerance time of the retina to acute transient ischaemia is many times higher than that of the brain and that occlusion of the central retinal artery does not lead to irreversible axonal damage if present for fewer than 90 minutes.

Despite very low IOP at the time of trephination, $20.8 \%$ of phakic patients experienced some amount of positive posterior pressure. The absence of positive pressure in all pseudophakic patients is due to the absence of the volume of the lens combined with an adequate dispersal of the anaesthetic and sometimes the lower volume of the vitreous when vitrectomy was already performed. When the lens is still present, positive posterior pressure does not depend on preoperative IOP and appears sometimes in patients with IOP below $10 \mathrm{~mm} \mathrm{Hg}$. This is probably due to other factors such as compression by the blepharostat which may participate in the mechanism of this posterior compression. Murdoch ${ }^{30}$ reported that the rate of intraoperative posterior pressure was less in cataract extraction after peribulbar than after retrobulbar anaesthesia. It would be interesting to compare the rate of positive posterior pressure in patients grafted under peribulbar or general anaesthesia. In our phakic patients this posterior pressure is sufficient to hinder capsulorhexis in $20.5 \%$ of open sky extracapsular extractions but is not sufficient to provoke vitreous loss in cases of radial tears. Consequently, even when IOP is very low, we recommend an intravenous perfusion of mannitol at the beginning of surgery when extracapsular extraction is needed or to perform capsulorhexis when possible in a closed system-that is, before trephination as proposed by Malbran et al. ${ }^{31}$
Another confirmation of the effectiveness of the compression is the very low incidence of chemosis $(6 \%)$ in our series with injection of large volumes of anaesthetic agents. In a prospective evaluation of 1000 low volume peribulbar anaesthesia, Agrawal and Athanikar $^{32}$ reported a $12.7 \%$ incidence of chemosis and Teichmann and Uthoff ${ }^{33}$ reported a 30\% incidence after retrobulbar anaesthesia. This is an important point as a higher incidence of chemosis may hinder the trephination when a limbal suction trephine system is used (Hanna trephine). Chemosis in our series was always minor and never hindered the trephination.

Our study suggests that very slow peribulbar injection with high volume combined with long compression is an effective and safe means of anaesthesia for keratoplasties.

The authors thank Mr Richard Medeiros for his advice in editing the manuscript.

1 Davis DB, Mandel MR. Posterior peribulbar anaesthesia: an alternative to retrobulbar anaesthesia. $\mathcal{F}$ Cataract Refract Surg 1986;12:182-4.

2 Weiss JL, Deichman CB. A comparison of retrobulbar and periocular anaesthesia for cataract surgery. Arch Ophthalmol 1989;107:96-8.

3 Burdon MA, McDonnell P. A survey of corneal graft practice in the United Kingdom. Eye 1995;9:6-12.

4 Price FW Jr, Whitson WE, Ahad KA, et al. Suprachoroidal haemorrhage in penetrating keratoplasty. Ophthalmic Surg 1994;25:521-5.

5 Ingraham HJ, Donnenfeld ED, Perry HD. Massive suprachoroidal hemorrhage in penetrating keratoplasty. $A m$ f Ophthalmol 1989;108:670-5.

6 Gloor B, Kalman A. Choroidal effusion and expulsive hemorrhage in penetrating interventions-lesson from 26 patients. Klin Monatsbl Augenheilkd 1993;202:224-37.

7 Davis DB 2nd, Mandel MR. Efficacy and complication rate of 16,224 consecutive peribulbar blocks. A prospective multicenter study. 7 Cataract Refract Surg 1994;20:327-37.

multicenter study. 7 Cataract Refract Surg 1994;20:327-37.
8 Wang HS. Peribulbar anaesthesia for ophthalmic procedures. F Cataract Refract Surg 1988;14:441-3.

9 Nicoll JMV, Treuren B, Acharya PA, et al. Retrobulbar anaesthesia: the role of hyaluronidase. Anesth Analg 1986;65:1324-8

10 Krause M, Weindler J, Ruprecht KW. Does warming of anaesthetic solutions improve analgesia and akinesia in retrobulbar anaesthesia? Ophthalmology 1997;104:429-32.

11 Weiss JL, Deichman CB. A comparison of retrobulbar and periocular anaesthesia for cataract surgery. Arch Ophthalmol 1989;107:96-8.

12 Aquavella JV. Outpatient corneal surgery. Int Ophthalmol Clin 1988;28:184-7.

13 Collie DM. Outpatient penetrating keratoplasty. Aust NZ f Ophthalmol 1989;17:373-7.

14 Yavitz E. Topical and intracameral anesthesia for corneal transplants (letter). f Cataract Refract Surg 1997;23:1435.

15 Morsman CD, Holden R. The effects of adrenaline, hyaluronidase and age on peribulbar anaesthesia. Eye $1992 ; 6: 290-2$

16 Chin GN, Almquist HT. Bupivacaine and lidocaine retrobulbar anaesthesia. Ophthalmology 1983;90:369-72.

17 Smith PH, Smith ER. A comparison of etidocaine and lidocaine for retrobulbar anaesthesia. Ophthalmic Surg 1983;14: 569-74

18 Smith PH, Kemp P, Smith ER. A comparison of retrobulbar block produced by etidocaine $1 \%$ and by a mixture of lidocaine $2 \%$ and bupivacaine $0.75 \%$. Ophthalmic Surg 1987; 18: 106-10.

19 Abelson MB, Mandel E, Paradis A, et al. The effect of hyaluronidase on akinesia during cataract surgery. Ophthalmic Surg 1989;20:325-6.

20 Sarvela J, Nikki P. Hyaluronidase improves regional ophthalmic anaesthesia with etidocaine. Can $f$ Anaesth 1992;39:920-4

21 Davis PL, O'Connor JP. Peribulbar block for cataract surgery: a prospective double-blind study of two local anaesthetics. Can f Ophthalmol 1989;24:155-8.

22 Arnold PN. Prospective study of a single-injection peribulbar technique. F Cataract Refract Surg 1992;18:157-61.

23 McDonnell PJ, Quigley HA, Maumenee AE, et al. The Honan intraocular pressure reducer. An experimental study. Arch Ophthalmol 1985;103:422-5.

24 Schriver PA, Sinha S, Galusha JH. Prospective study of the effectiveness of retrobulbar and peribulbar anaesthesia for anterior segment surgery. F Cataract Refract Surg 1992;18: $162-5$.

25 Ingraham HJ, Donnenfeld ED, Perry HD. Massive suprachoroidal haemorrhage in penetrating keratoplasty. $A m \mathcal{F}$ Ophthalmol 1989;108:670-5. 
26 Morgan JE, Chandna A. Intraocular pressure after peribulbar anaesthesia: is the Honan balloon necessary? $\mathrm{Br} F \mathrm{Oph}-$ bar anaesthesia: is the

27 Bowman R, Liu C, Sarkies N. Intraocular pressure changes after peribulbar injections with and without ocular compression. Br f Ophthalmol 1996;80:394-7.

28 Palay DA, Stulting RD. The effect of external ocular compression on intraocular pressure following retrobulbar anaesthesia. Ophthalmic Surg 1986;21:503-7.

29 Hayreh SS, Weingeist TA. Experimental occlusion of the central artery of the retina. IV: Retinal tolerance time to acute ischaemia. Br F Ophthalmol 1980;64:818-25.
30 Murdoch IE. Peribulbar versus retrobulbar anaesthesia. Eye 1990;4:445-9.

31 Malbran ES, Malbran E, Buonsanti J, Adrogue E. Closed-system phacoemulsification and posterior chamber implant combined with penetrating keratoplasty. Ophthalmic Surg 1993;24:403-6

32 Agrawal V, Athanikar NS. Single injection, low volume periocular anaesthesia in 1000 cases. F Cataract Refract Surg 1994;20:61-3.

33 Teichmann KD, Uthoff D. Retrobulbar (intraconal) anaesthesia with a curved needle: technique and results. $\mathcal{F}$ Cataract Refract Surg 1994;20:54-60.

\section{Contributors please note:}

Communications from the UK, Republic of Ireland, Australasia, Asia, Africa, Japan, and the Middle East should be sent to the Editor, British Journal of Ophthalmology, Department of Ophthalmology, University of Aberdeen, Medical School, Foresterhill, Aberdeen AB25 2ZD, Scotland, UK (Tel: 01224 663812; Fax: 01224 663832).

Communications from Western Europe, Eastern Europe, the former Soviet Union, and Scandinavia should be sent to Professor A Kijlstra, Associate editor, The Netherlands Ophthalmic Research Institute, PO Box 12141, Meibergdreef 9 , 1100 AC Amsterdam, Netherlands (Tel: +31 20 5664535; Fax: +31 20 6913401).

Communications from the USA, Canada, and South America should be sent to Professor C Hoyt, Associate editor, University of California, UCSF Ophthalmology Department, Pediatric Ophthalmology, 400 Parnassus Avenue, Room 702 A, Box 0344, San Francisco, CA 94143, USA (Tel: +415 476 1289/1921; Fax: +415 502 6468). 